Article

\title{
Fine Mapping Identifies SmFAS Encoding an Anthocyanidin Synthase as a Putative Candidate Gene for Flower Purple Color in Solanum melongena $\mathrm{L}$.
}

\author{
Mengqiang Chen ${ }^{1,2,+}$, Mengyun $\mathrm{Xu}{ }^{2,+}$, Yao Xiao ${ }^{2}$, Dandan Cui ${ }^{2}$, Yongqiang Qin ${ }^{2}$, Jiaqi Wu ${ }^{2}$, \\ Wenyi Wang ${ }^{3, *}$ and Guoping Wang ${ }^{1,2, *}$ \\ 1 Key Laboratory of Biology and Germplasm Enhancement of Horticultural Crops in South China, \\ Ministry of Agriculture, College of Horticulture, South China Agricultural University, \\ Guangzhou 510642, China; chenmq068@163.com \\ 2 College of Horticulture, South China Agricultural University, Guangzhou 510642, China; \\ 11116047@zju.edu.cn (M.X.); xiaoyao1990@cau.edu.cn (Y.X.); cuidan0627@163.com (D.C.); \\ yqg_qin@163.com (Y.Q.); wujiaqi_3764@163.com (J.W.) \\ 3 Department of Plant Science, Weizmann Institute of Science, Rehovot 76100, Israel \\ * Correspondence: wang.wenyi@weizmann.ac.il (W.W.); gpwang@scau.edu.cn (G.W.) \\ + These authors contributed equally to this work.
}

Received: 7 February 2018; Accepted: 6 March 2018; Published: 9 March 2018

\begin{abstract}
Anthocyanins are the main pigments in flowers and fruits. These pigments are responsible for the red, red-purple, violet, and purple color in plants, and act as insect and animal attractants. In this study, phenotypic analysis of the purple flower color in eggplant indicated that the flower color is controlled by a single dominant gene, $F A S$. Using an $\mathrm{F}_{2}$ mapping population derived from a cross between purple-flowered 'Blacknite' and white-flowered 'Small Round', Flower Anthocyanidin Synthase (FAS) was fine mapped to an approximately 165.6-kb region between InDel marker Indel8-11 and Cleaved Amplified Polymorphic Sequences (CAPS) marker Efc8-32 on Chromosome 8. On the basis of bioinformatic analysis, 29 genes were subsequently located in the $F A S$ target region, among which were two potential Anthocyanidin Synthase (ANS) gene candidates. Allelic sequence comparison results showed that one ANS gene (Sme2.5_01638.1_g00003.1) was conserved in promoter and coding sequences without any nucleotide change between parents, whereas four single-nucleotide polymorphisms were detected in another ANS gene (Sme2.5_01638.1_g00005.1). Crucially, a single base pair deletion at site 438 resulted in premature termination of $F A S$, leading to the loss of anthocyanin accumulation. In addition, FAS displayed strong expression in purple flowers compared with white flowers and other tissues. Collectively, our results indicate that Sme2.5_01638.1_g00005.1 is a good candidate gene for $F A S$, which controls anthocyanidin synthase in eggplant flowers. The present study provides information for further potential facilitate genetic engineering for improvement of anthocyanin levels in plants.
\end{abstract}

Keywords: anthocyanidin synthase; eggplant; fine mapping; flower color

\section{Introduction}

Three major groups of chemical pigments-betalains, carotenoids, and anthocyanins-are responsible for the colors of flowers [1-3]. Of these, anthocyanins belong to a large group of phenolic secondary metabolites known as flavonoids, which are responsible for the red, red-purple, violet, purple, and blue colors found in many flowers and fruits [3,4]. Anthocyanins are generally synthesized in the cytosol of epidermal cells via the phenylpropanoid pathway and are subsequently transported to 
the vacuole or cell walls where they are stored. The biosynthesis of anthocyanins has been well studied in many plant species, and the key regulatory genes and relevant transcriptional factors controlling the pathway have been isolated over the past few decades $[1,5,6]$.

Eggplant (Solanum melongena L.), an important horticultural crop worldwide, is currently widely cultivated in Asia, Africa, North America, and Europe. Eggplant not only provides numerous compounds beneficial to health, including vitamins and minerals, but also contains important phytonutrients such caffeic and chlorogenic acids and flavonoids [7-9]. Eggplants with purple flowers and fruits are rich in anthocyanins, which are among the most important secondary metabolites and beneficial to human health. Moreover, the color of eggplant flowers is generally linked to yield, fruit coloration, and disease resistance. Therefore, exploring DNA makers or genetic loci related to flower color is considered as an important approach in rapid breeding via marker-assisted selection (MAS).

In recent years, with the release of the draft genomes of many plants, several genes and quantitative trait loci (QTL) that control flower and fruit color have been reported in different plant species [10-14]. Furthermore, given that anthocyanin biosynthesis is currently an important focus of plant secondary metabolism, intensive efforts have been made to identify the key genes of the respective biosynthetic pathways. The anthocyanin biosynthetic pathway (Figure 1), which starts with phenylalanine, contains five key enzyme genes: chalcone synthase $(\mathrm{CHS})$, chalcone isomerase $(\mathrm{CHI})$, flavanone-3-hydroxylase $(F 3 H)$ or flavanone $3^{\prime}$-hydroxylase $\left(F 3^{\prime} H\right)$ or flavanone $3^{\prime}, 5^{\prime}$-hydroxylase $\left(F 3^{\prime} 5^{\prime} H\right)$, dihydroflavonol 4-reductase (DFR), and anthocyanidin synthase (ANS). Notably, ANS, a 2-oxoglutarate and $\mathrm{Fe}^{2+}$-dependent oxygenase, which is the last key enzyme in the anthocyanin biosynthetic pathway, catalyzes the transformation of colorless leucoanthocyanidin to anthocyanidins and proanthocyanidins. Functional defects in (or the absence of) ANS affects plant color formation, resulting in colorless or white organs, suggesting its importance in the formation of color in plants [15]. A notable physiological function of the anthocyanin pigments is recruitment of polleninator and seed dispersers [5], moreover, anthocyanin pigments play an important role in signaling between plants and micobes, UV protection [5]. Thus, it is desirable to explore anthocyanin biosynthesis mechanism in plants. In the present study, a Flower Anthocyanidin Synthase (FAS) locus was cloned from a 165.6-kb region on Chromosome 8 using an $\mathrm{F}_{2}$ mapping population derived from a cross between the cultivars Blacknite (BN: purple flower, purple fruit) and Small Round (SR: white flower, green fruit). On the basis of bioinformatic and expression analyses, a mutation in an ANS gene, resulting in premature termination of the predicted polypeptide, was shown to be responsible for the white color in eggplant flowers. 


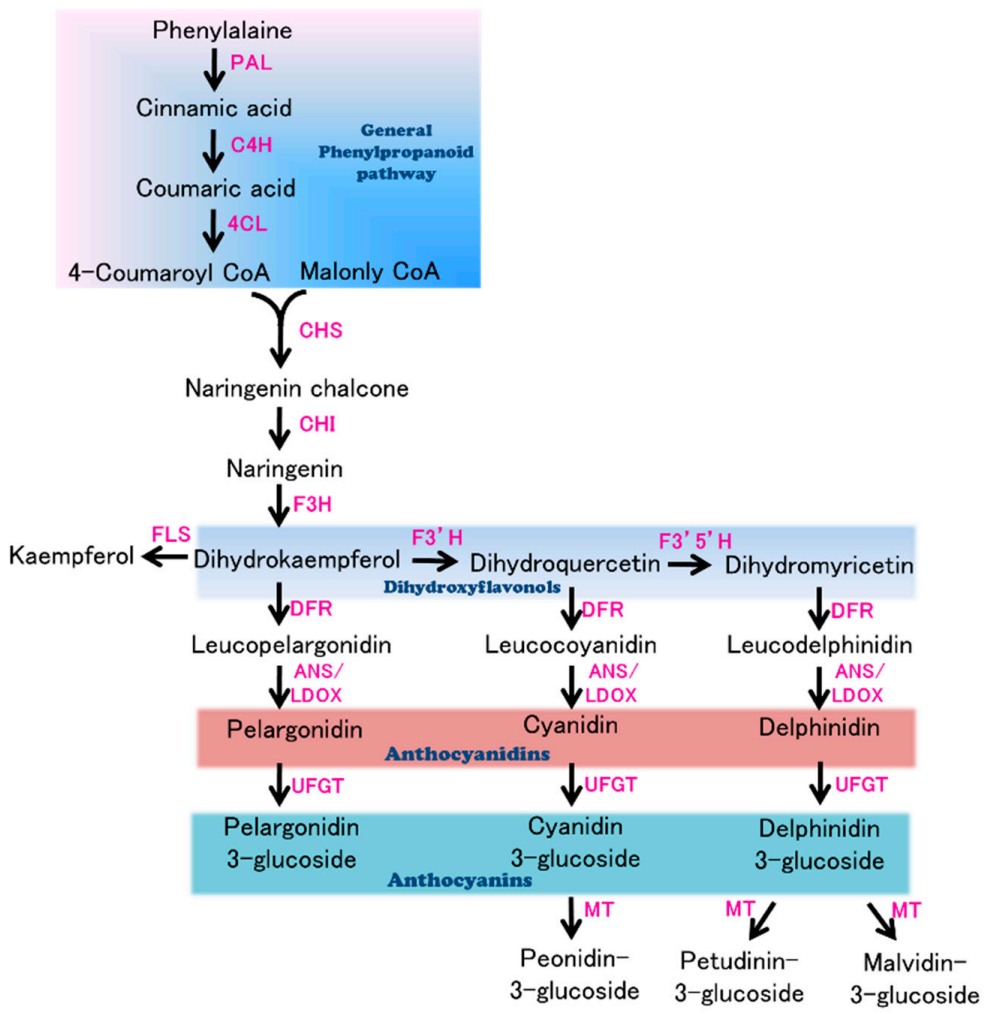

Figure 1. Biosynthesis of anthocyanin in plants. Enzymes are indicated in pink text. Abbreviations: $\mathrm{PAL}$, phenylalanine ammonialyase; $\mathrm{C} 4 \mathrm{H}$, cinnamate-4-hydroxylase; $4 \mathrm{CL}, 4$ coumarate $\mathrm{CoA}$ ligase; CHS, chalcone synthase; $\mathrm{CHI}$, chalcone isomerase; $\mathrm{F} 3 \mathrm{H}$, flavanone 3-hydroxylase; FLS, flavonol synthase; F3' $\mathrm{H}$, flavanone $3^{\prime}$-hydroxylase; F3' $5^{\prime} \mathrm{H}$, flavanone $3^{\prime}, 5^{\prime}$-hydroxylase; DFR, dihydroflavonol 4-reductase; ANS/LDOX, anthocyanidin synthase/leucoanthocyanidin dioxygenase; UFGT, UDP-flavonoid glucosyl transferase; MT, methyl transferase.

\section{Materials and Methods}

\subsection{Plant Materials and Mapping Populations}

$\mathrm{F}_{2}$ mapping population, containing 3133 lines, was developed from a cross between the cultivars Blacknite (BN: purple flower, deep purple fruit, purple stem and purple calyx, collected in Australia) and Small Round (SR: white flower, green fruit, green stem and green calyx, originated in south of china), and used for linkage and genetic mapping analysis. An additional 14 purple or white flower cultivars were used for mutation analysis in the target region. All eggplants were grown on the experimental field of South China Agricultural University in Guangzhou $\left(23^{\circ} 20^{\prime} \mathrm{N} 113^{\circ} 30^{\prime} \mathrm{E}\right.$, subtropical climate, China) from spring to summer.

\subsection{DNA Extraction and SSR Identification}

Genomic DNA was extracted from young leaves using the Cetyl trimethylammonium bromide (CTAB) method with some modifications. All of the primers used in this study were designed by SSRHunter1.3 (http://en.bio-soft.net/dna/SSRHunter.html) and Primer Premier 5.0 software (Premier Biosoft International, Palo Alto, CA, USA), then synthesized by Sangon Bitotech Co., Ltd. (Guangzhou, China). All primers used in this study are listed in Supplemental Table S1. Each $10 \mu \mathrm{L}$ PCR reaction contained $5.6 \mu \mathrm{L}$ water, $1.0 \mu \mathrm{L} 10 \times$ buffer $\left(\mathrm{Mg}^{2+}\right), 1 \mu \mathrm{L}$ dNTPs $(10 \mathrm{mM}), 1 \mu \mathrm{L}$ each of upstream and downstream primers $(1 \mu \mathrm{M}), 0.4 \mu \mathrm{L}$ Taq DNA polymerase $(10 \mathrm{U} / \mu \mathrm{L})$. The PCR amplification was performed with the following program: $94{ }^{\circ} \mathrm{C}$ for $5 \mathrm{~min}$ followed by 36 cycles of 
$94{ }^{\circ} \mathrm{C}$ for $30 \mathrm{~s}, 55^{\circ} \mathrm{C}$ for $30 \mathrm{~s}$, and $72{ }^{\circ} \mathrm{C}$ for $1 \mathrm{~min}$ with a final extension at $72{ }^{\circ} \mathrm{C}$ for $10 \mathrm{~min}$. Subsequently, the PCR amplification products were subjected to electrophoresis in a $6 \%$ polyacrylamide gel.

\subsection{Mapping Strategy and Linkage Analysis}

Over 1500 eggplant simple sequence repeat (SSR) markers developed by our laboratory were used to screen for polymorphism between parental lines. Then the polymorphic markers were used to genotype the individuals of $\mathrm{F}_{2}$ mapping population. A group of 40 individual plants were randomly selected for preliminary mapping. The chromosome position of the linked marker EMJ316 was inferred by the similarity of its marker sequence with tomato genome sequence and the genome between tomato and eggplant. Eggplant draft genome sequence was used to develop a series of new SSR markers around the target region. The obtained polymorphic SSR markers were subsequently used to genotype $174 \mathrm{~F}_{2}$ plants. Preliminary mapping analysis was performed with Jounmap3.0 software (Plant Research International BV, Wageningen, The Netherlands).

When the available SSR markers in the target region were exhausted, BN and SR were submitted to re-sequence on the Illumina DNA sequencing platform by Biomaker Technology Company (Beijing, China). According to the information of sequence polymorphism within the FAS target region, InDel and Single nucleotide polymorphism (SNP)-based derived cleaved amplified polymorphic sequence (dCAPS) markers were continuously designed. Two robust boundary markers spanning the $F A S$ region were used to screen $3133 \mathrm{~F}_{2}$ population for recombination plants to narrow the interval containing target gene. The genetic distance was calculated by the Kosambi function.

\subsection{Candidate Gene Prediction and Identification}

Candidate gene prediction was performed by the online program FGENESSG, eggplant and tomato genome browser (http:/ / eggplant.kazusa.or.jp/, https:/ / solgenomics.net/organism/Solan um_lycopersicum/genome), and BLASTx of NCBI (National Center for Biotechnology Information, https:/ /blast.ncbi.nlm.nih.gov/Blast.cgi). To clone sequences of the two potential candidate genes, primers were designed by software Primer Premier 5.0 in the target region. Gene alignments among different materials were performed using CLUSTALX1.8 (CNRS/INSERM/ULP, Illkirch Cedex, France) with default settings. All eggplant amino acid sequences were obtained from online draft genome sequence database (http:/ / eggplant.kazusa.or.jp/).

\subsection{Quantitative Real-Time RT-PCR Analysis of Candidate Genes}

Total RNAs were extracted from different tissues (root, stem, leaf, flower, and fruit) of BN, SR and its crossbred $F_{1}$ plants using Hipure Plant RNA kits according to the manufacturer's instructions. Primers were designed by software Primer Premier 5.0. Quantitative real-time RT-PCR (qRT-PCR) analysis was conducted with the Lightcycler 480 machine (Roche, Sussex, UK) using SYBR Green I. The expression of genes was calculated with $2^{-\Delta \Delta \mathrm{Ct}}$ method. The eggplant Glyceraldehyde-3-phosphate dehydrogenase $(G A D P H)$ gene was used as an internal reference. Each experiment was had three biological and technical repetitions. The specific primers for qRT-PCR are listed in Supplementary Table S1.

\section{Results}

\subsection{Inheritance of SMFAS}

Eggplant cultivars Blacknite (BN) and Small Round (SR) were used to generate $F_{1}$ and $F_{2}$ population (Figure 2). All the $\mathrm{F}_{1}$ plants of reciprocal crosses exhibited purple-colored flowers, suggesting the dominant nature of purple to while flower color. Of $174 \mathrm{~F}_{2}$ individuals, flower color segregated as 137 purple to 37 white, which is consistent with a 3:1 Mendelian segregation ratio (Table 1), indicating that the flower color in eggplant is controlled by a single dominant gene, which we designated as SmFAS (Flower Anthocyanidin Synthase). 


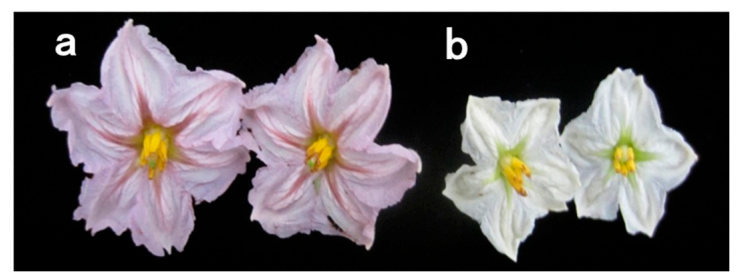

Figure 2. Flower color of parental lines. (a) The purple flower in Blacknite (BN); (b) the white flower in Small Round (SR).

Table 1. Segregation of flower color in the $F_{1}$ and $F_{2}$ population

\begin{tabular}{cccccc}
\hline Population & Plant Tested & Purple:White & Mendelian Expectations & $\mathbf{X}^{2}$ & $p$ \\
\hline BN (purple) $\times$ SR (white) & & & & & \\
$\mathrm{F}_{1}$ & all & all purple & $1: 0$ & & \\
$\mathrm{~F}_{2}$ & 174 & $137: 37$ & $3: 1$ & 1.295 & 0.255 \\
\hline
\end{tabular}

BN: Blacknite; SR: Small Round.

\subsection{Linkage Mapping of SmFAS}

Initially, 1052 eggplant SSR markers developed in our laboratory were used to screen polymorphic markers. The polyacrylamide gel electrophoresis (PAGE) results revealed that $761(72.9 \%)$ markers were non-polymorphic, $211(20.0 \%)$ could not be amplified, and the remaining $74(7.7 \%)$ appeared to be polymorphic between parental lines. We used these 74 polymorphic SSR makers to genotype 40 random $\mathrm{F}_{2}$ mapping individuals. Linkage analysis indicated that the SmFAS locus was linked to the EMJ316 marker, with a genetic distance is $26.9 \mathrm{cM}$ (Figure 3a). Detailed information of the map locations of eggplant SSR polymorphic markers is presented in Figure S1.

To identify markers flanking SmFAS, a series of new SSR markers in the target region were continuously developed near the EMJ316 marker. Seven new polymorphic SSR markers were subsequently used to screen $174 \mathrm{~F}_{2}$ plants. Among these, ETM8-17 and ETM8-34 were located 4.0.0 and $17.0 \mathrm{cM}$ from the SmFAS locus (Figure $3 \mathrm{~b}$ ). Through a comparison with the eggplant draft genome, ETM8-17 and ETM8-34 were consistent with the scaffolds of Sme2.5_03884.1 and Sme2.5_05139.1, and the physical distance between the two markers was $\sim 423.6 \mathrm{~kb}$ (Figure $3 \mathrm{c}$ ).

To precisely narrow down the region surrounding SmFAS, Indel marker Indel8-7 and SSR marker ETM8-35 were used to genotype $3133 \mathrm{~F}_{2}$ plants, and 69 recombinant plants were identified. Finally, three Indel markers and three CAPS makers between ETM8-17 and ETM8-34 were developed to identify the 69 recombinant plants. The results showed that Indel8-11, Efc8-19, Efc8-12, Indel8-17, and Efc8-32 were in complete genetic linkage with the SmFAS locus without any recombination events. Thus, the SmFAS locus was located in a region of $\sim 165.6 \mathrm{~kb}$ between Indel8-11 and Efc8-32 (Figure 3d).

\subsection{Candidate Genes for Purple Flower Color in Eggplant}

On tomato genome, there were 24 annotated genes within the corresponding region spanned by marker Indel8-11 and Efc8-32, and one gene Solyc08g080040.2.1 was predicted as anthocyanidin synthase. Six eggplant scaffolds located in the target region contained 29 genes. Interestingly, two ANS genes (Sme2.5_01638.1_g00003.1 and Sme2.5_01638.1_g00005.1) were predicted.

Among the 29 predicted genes of eggplant, the coding sequence (CDS) of 22 genes including Sme2.5_01638.1_g00003.1 had no any nucleotide difference between two parents according to the re-sequencing information (Table 2). The CDS of six genes existed single nucleotide polymorphisms (SNPs) which resulted in no or one amino acid substitution but possibly did not cause the loss of gene function. However, four SNPs were detected for the gene Sme2.5_01638.1_g00005.1. Among these, mutations at positions $+65 \mathrm{bp}$ and $+141 \mathrm{bp}$ resulted in changes in the $23 \mathrm{rd}$ and 47 th amino acid residues, 
from Ala (A) to (Val) V and from (Asp) D to (Glu) E, respectively (Figure 3e,f). More crucially, one single base pair deletion at site 438 resulted in premature termination of SmFAS (Figure 3g), which leads to a malfunction of ANS. These preliminary results indicate that Sme2.5_01638.1_g00005.1 is the best candidate gene for SmFAS.

To explore whether the color of flower is consistent with the nucleotide insertion/deletion mutation in Sme2.5_01638.1_g00005.1, we further PCR-amplified the full length of FAS gene of 16 eggplant cultigens with purple or white flowers (Table 3). The SNPs and insertion/deletion between two parents were confirmed once again. For all purple flower eggplants, none SNP was found in Sme2.5_01638.1_g00005.1 compared with BN; whereas in two other white flower cultivars, the deletion in 438 site resulted in premature termination of FAS was undetectable (Figure 4), suggesting that the white flower caused by the deletion of site 438 of SmFAS was genotype-specific in cultivar SR.

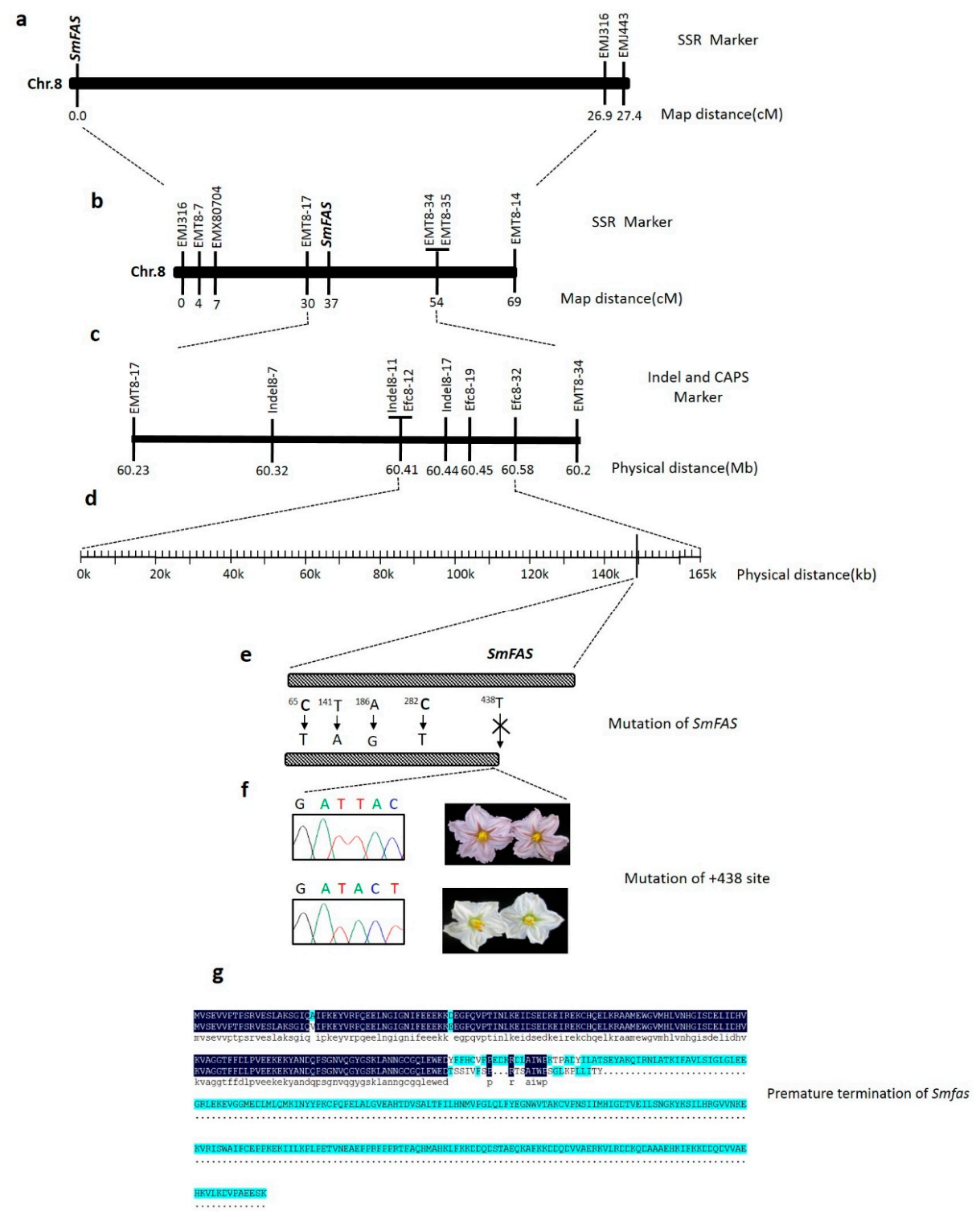

Figure 3. Genetic linkage map of Flower Anthocyanidin Synthase (FAS) locus. (a) Chromosomal location of FAS locus; $(\mathbf{b}, \mathbf{c})$ framework map based on $\mathrm{F}_{2}$ family; (d) high-resolution map of FAS locus into a $\sim 165.6 \mathrm{~kb}$ between Indel8-11 and Efc8-32; (e) the structure of FAS shows that four single nucleotide polymorphisms (SNPs)were detected between parents in the coding sequence (CDS), and a single base pair deletion in site 438; (f) the site 438 of $F A S$ in parents and their sequencing chromatograms-upper panel: BN; lower panel: SR. (g) the mutation in site 438 resulted in premature termination of FAS. 
Table 2. Candidates' annotations in the Flower Anthocyanidin Synthase (FAS )target region on Chromosome 8

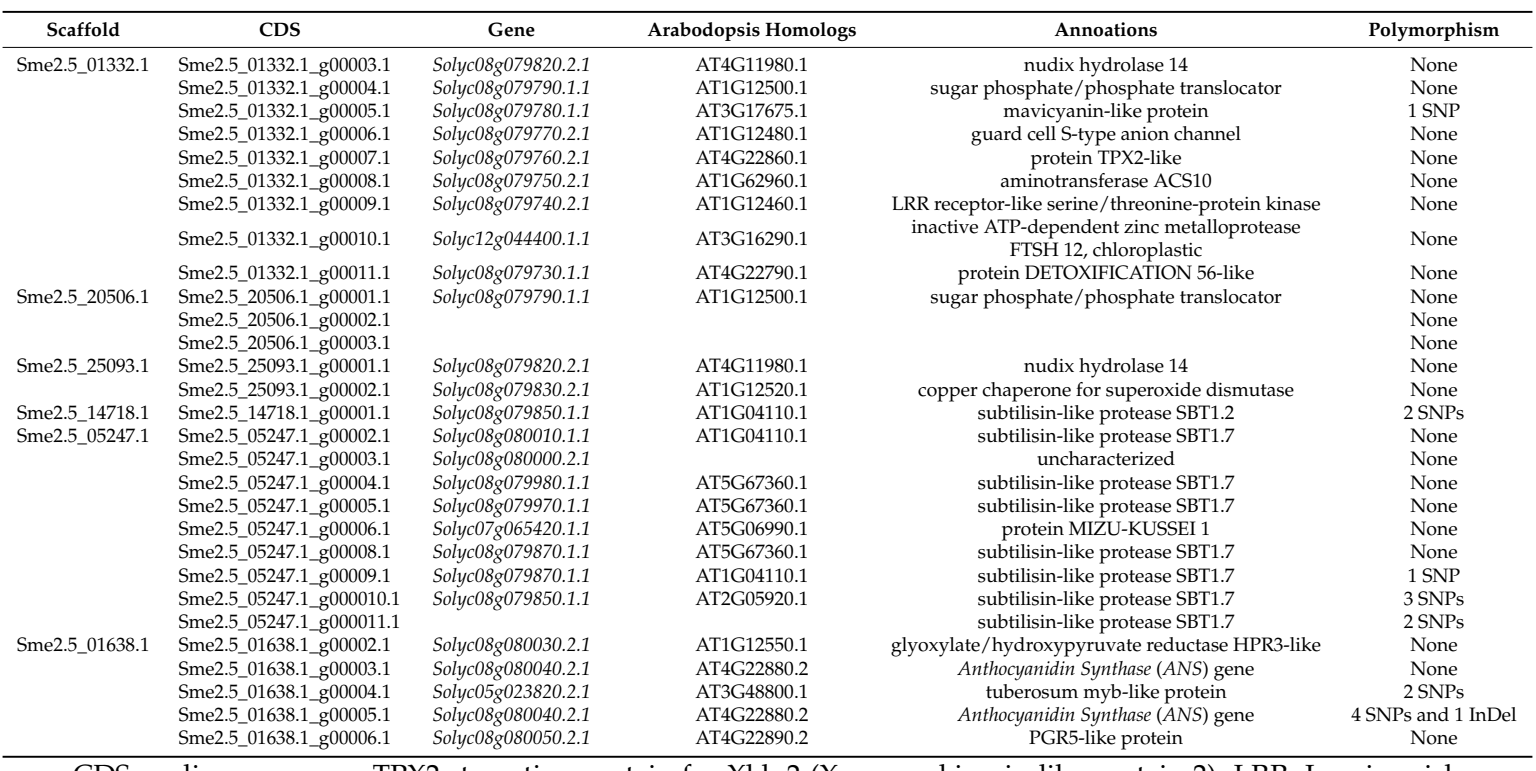

CDS: coding sequence; TPX2: targeting protein for Xklp2 (Xenopus kinesin-like protein 2); LRR: Leucine-rich repeat receptor; FTSH: filamentation temperature sensitive; PGR5: Proton Gradient Regulation5; InDel: insertion-deletion.

Table 3. Sample of 16 eggplant cultigens with purple and white flower used for Flower Anthocyanidin Synthase (ANS) mutation identification.

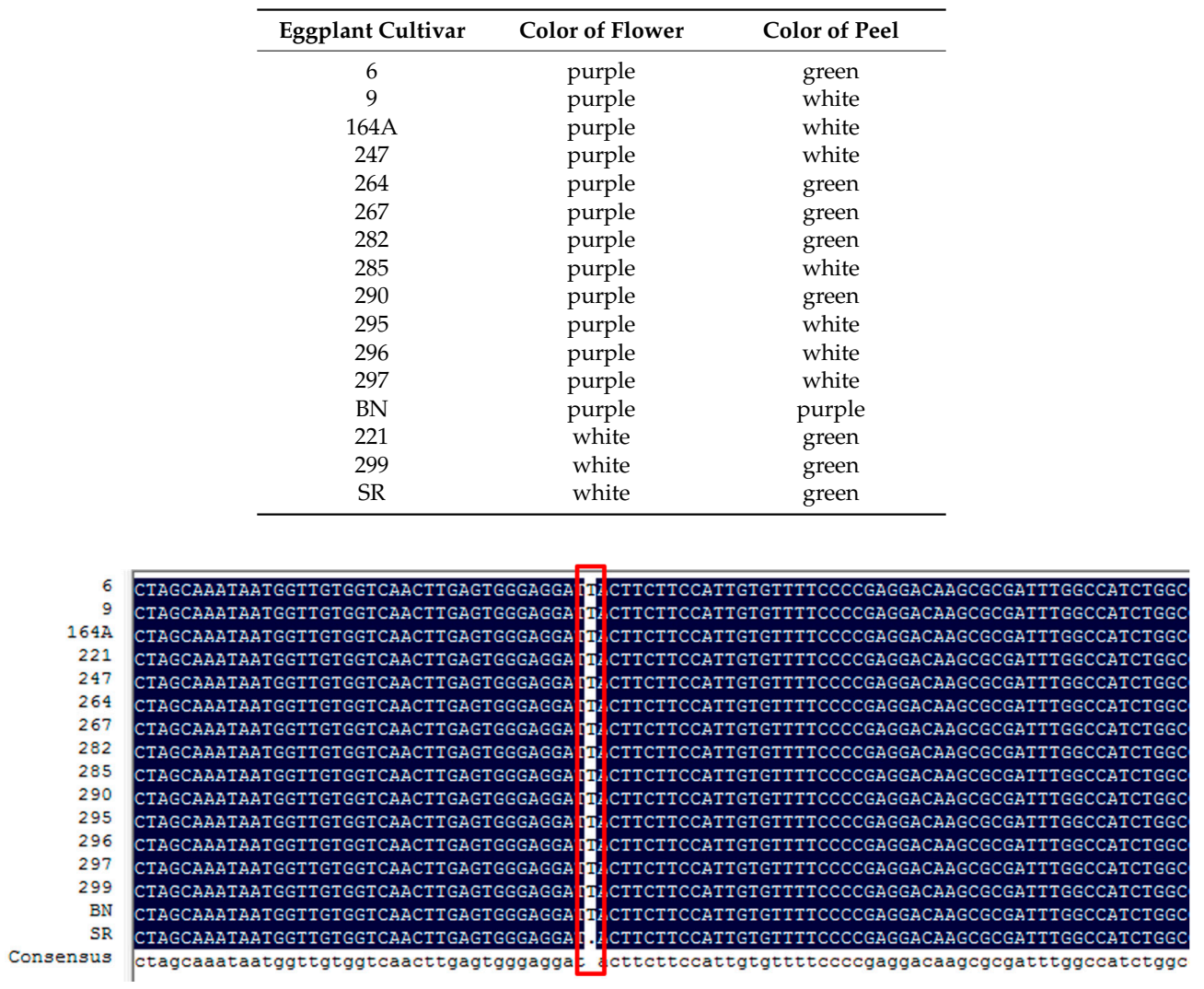

Figure 4. Comparison of Sme2.5_01638.1_g00005.1 (ANS) gene in 16 eggplants with purple and while flower. 


\subsection{Expression Analysis of Two ANS Genes in Various Materials and Tissues}

As described in the previous paragraph, there are two potential candidate Anthocyanidin Synthase (ANS) genes in the region targeted in this study. We used qRT-PCR to further investigate the expression levels of both candidate ANS genes in different tissues (roots, stems, leaves, flowers, and fruits) from parental lines and their $\mathrm{F}_{2}$ progenies showing various phenotypes, such as white flower with green fruit, purple flower with green fruit, purple flower with purple-black fruit. The results revealed Sme2.5_01638.1_g00003.1 to be expressed very weakly in all organs without significant difference (Figure 5a). Whereas Sme2.5_01638.1_g00005.1 displayed strong expression, particularly in flowers compared with roots, stems, leaves, and fruit in all materials (Figure 5b). Notably, Sme2.5_01638.1_g00005.1 showed significant differences in expression profiles between purple and white flowers, which was consistent with the flower phenotype. This further indicates that Sme2.5_01638.1_g00005.1 is the most probable candidate gene for FAS. Moreover, the data also indicated that different types of ANS may be present in flowers and fruits, since expression of SmFAS is lower in green fruit compared with purple fruit.

(a)

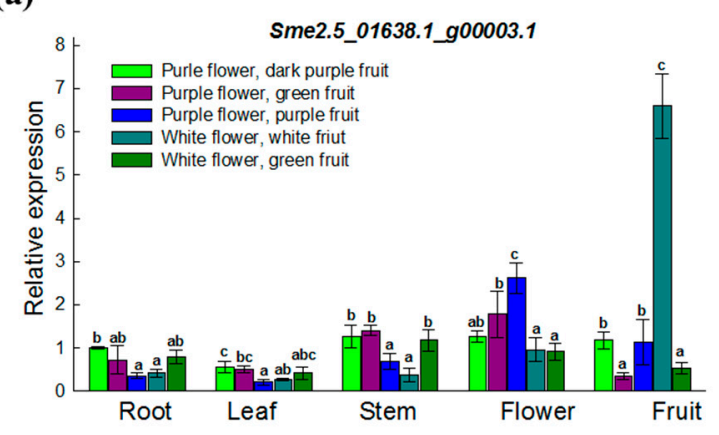

(b)

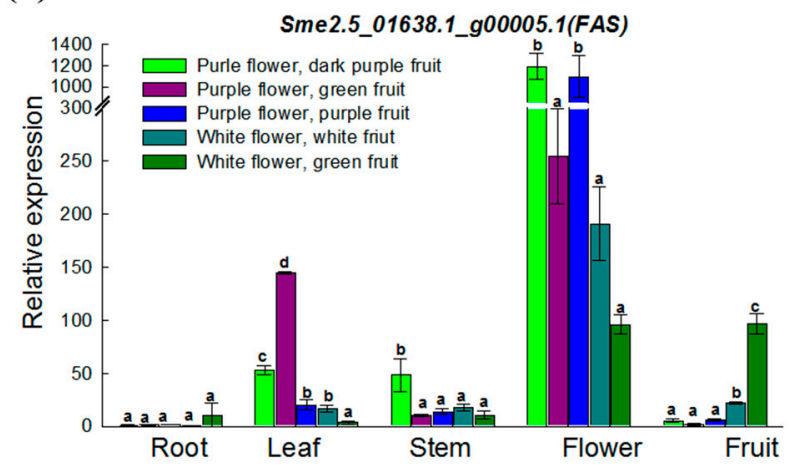

Figure 5. Expression analysis of the two ANS candidates in parental lines, $\mathrm{F}_{2}$ progenies with different phenotypes in various tissues (root, leaf, stem, flower, fruit) by qRT-PCR. (a) Sme2.5_01638.1_g00003.1; (b) Sme2.5_01638.1_g00005.1. Data are expressed by mean of three biological replicates with error bars indicating the SD. Letter represent significant difference among the five phenotypes using (Analysis of variance) ANOVA. a, b, c and d: $p<0.05$, Student Newman-Keuls test.

\section{Discussion}

Flower color, which is used to attract insect pollinators, is an important trait of plants. Anthocyanidins are the most abundant flavonoid pigments that determine the flower color. The mechanisms behind the accumulation of floral pigments have been well-studied in several plants $[1,5,16,17]$. In the present study, using map-based cloning strategy, we delimited the Flower Anthocyanidin Synthase (FAS) locus to a 165.6-kb region on chromosome 8 in Solanum melongena L. Sequencing and expression analysis revealed that $F A S$ encoded an ANS. Results from this study 
support the notion that the dominant gene, FAS, controls the flower color in Solanum melongena L., which is consistent with the results of previous studies $[9,12,13]$.

Recently, a locus controlling the purple corolla in eggplant was mapped to chromosome 12 between two markers, gg9149_779 and emxC0904 [9]; this is different from the locus identified by us, which is located on chromosome 8 . In the study by Hirakawa, the candidate gene responsible for the purple corolla was a MYB-like transcription factor, which acts as an activator or repressor of gene expression, controlling the color of flowers in eggplant. In contrast, the gene controlling the purple flower trait identified by us is $A N S$, which is different from the transcriptional factor controlling the flower color in eggplant. In flowers, three kinds of transcriptional factors (R2R3-MYB, bHLH, and WD40) and their combinations that control anthocyanin synthesis have been intensively studied [18-21]. Among these, R2R3-MYB is generally considered to be closely associated with the biosynthesis and regulation of anthocyanins. For example, in gerbera plants, the overexpression of MYB10 led to a notable increase in the accumulation of anthocyanin [22,23].

Barchi et al. (2012) used an $\mathrm{F}_{2}$ population to map the quantitative trait loci (QTLs) for seven traits associated with anthocyanin content and identified 11 different QTL regions [24]. Among these, two loci located in chromosome 8, namely adaxial/abaxial leaf lamina anthocyanin and calyx anthocyanin. Subsequently, Cericola et al. (2014) identified 12 loci on 9 chromosomes responsible for anthocyanin pigmentation and fruit color by performing a genome-wide association analysis using 191 eggplant accessions and 384 SNP loci markers [25]. Notably, loci identified by Barchi and Cericola group were far away from the FAS mapped in this study. The reason for this is that the flower color of two parents in Barchi's study was purple of different levels. Whereas in Cericola's study, some eggplant with white flower were used in the study, locus of FAS has not yet to be found, the possible reason could be attributed to the low frequency of white flower caused by function loss of $F A S$ in natural population. In this study, two of three cultigens with white flower without deletion at position 438 of FAS gene. Similarly, the white flower loci mapped on chromosome 12 by Hirakawa et al. (2014) were also not detected in Cericola's study [9]. Collectively, the molecular mechanism underlying for white flower in eggplant might be complex.

Generally, the visible accumulation of anthocyanidins reflects the activity of the enzymes involved in the biosynthetic pathway [26]. We detected the expression of $F A S$ in the parental lines and in their $\mathrm{F}_{2}$ progenies with different phenotypes, such as white flower with green fruit, purple flower with green fruit, and purple flower with purple-black fruit. Furthermore, we also checked the expression in different tissues (roots, stems, leaves, flowers, and fruits), the results showed that FAS was strongly expressed in purple flowers (Figure $4 \mathrm{~b}$ ). In this respect, our results are consistent with those reported in the flowers of different species, such as maize, snapdragon, and petunia [27-29]. Generally, the expression of ANS was in consonance with the color shades in fruits and flowers. For example, in the purple organs, the expression was specifically upregulated compared to that in the pink or white organs in different plant species [26]. Similar results were also obtained in eggplant in our study. Moreover, during fruit maturation, the expression levels of anthocyanidin pathway genes, including ANS, were increased and were related to the accumulation of anthocyanidins in many plants, such as bilberry, mock strawberry, pea, snapdragon, and petunia [27,30-32]. These results were consistent with those observed for our candidate gene, SmFAS. Overall, these findings suggest that FAS is a gene associated with late stage of anthocyanin biosynthesis pathway, and is involved in the regulation of the flower color in eggplant (Figure 6). 


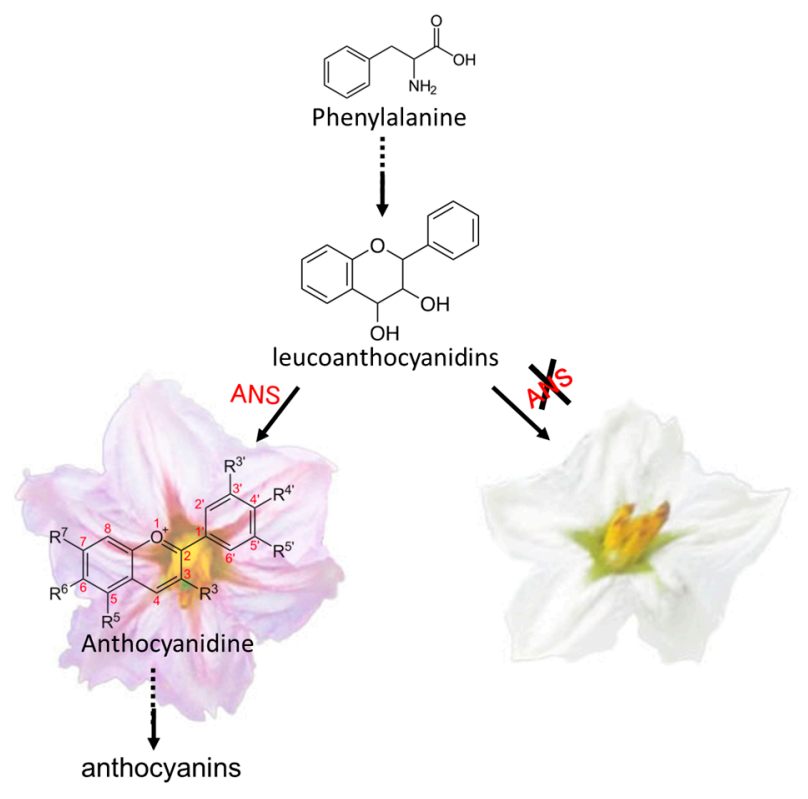

Figure 6. Functional defects or mutations in ANS influence the flower color formation, leading to white flower. The dashed arrow indicates several enzymatic reactions. The arrow represents specific enzymatic reaction. " $\mathbf{X}^{\prime \prime}$ represents fail to synthesize anthocyanidin due to malfunction of ANS gene.

Given the importance of ANS in the anthocyanidin biosynthesis pathway, the role of ANS has been intensively studied in several plants, such as Arabidopsis, apple, Lisianthus, strawberry, and pomegranate $[1,33,34]$. Functional defects or mutations in ANS often influence the color formation, leading to colorless or white organs. In apple, silencing of ANS led to significant loss of anthocyanins in transgenic plants. In Lisianthus, a 94 bp deletion mutation and frame shift in the ANS gene was confirmed to be associated with acyanic flowers [35]. Notably, Ben-Simhon et al. (2015) recently demonstrated that an insertion in the coding region of $P g L D O X$ (leucoanthocyanidin dioxygenase, also known as ANS) resulted in white anthocyanin-less phenotype in pomegranate [36]. This trait was further proven to be controlled by a recessive signal gene. In the present study, we observed that another single base pair deletion at position 438 of ANS resulted in its premature termination, and the expression levels of ANS in $\mathrm{F}_{2}$ progenies correlated with different phenotypes, suggesting that this mutation disrupts the normal transcription of gene, leading to the failure of anthocyanidin synthesis and generation of white flowers. We further checked the mutation site in 14 eggplant cultivars with purple and white flowers, and noticed that the mutation at position 438 , responsible for the premature termination of anthocyanidin synthase, was undetectable in all these eggplant cultivars, suggesting that mutation in ANS results in the white flower phenotype in the eggplant cultivar, SR. Moreover, the purple flower trait was identified to be controlled by a dominant signal gene. Taken together, our findings provide a better understanding of anthocyanin biosynthesis in eggplant and may facilitate genetic engineering of plans for enhanced anthocyanin content.

Supplementary Materials: Supplementary materials can be found at www.mdpi.com/1422-0067/19/3/789/s1.

Acknowledgments: This study is supported by the Projects of Guangdong Agricultural Department (2017LM2148), Guangdong Educational Department (2014KGJHZ004), the International Cooperation Project of the Ministry of Science and Technology of China (2010DFA32190) and the National Natural Science Fund $(31171957,30911120052)$.

Author Contributions: Guoping Wang and Mengqiang Chen conceived and designed the research, analyzed data. Mengqiang Chen performed population and marker development. Mengyun Xu, Yao Xiao, and Dandan Cui participated in the DNA extraction and population development. Yongqiang Qin and Jiaqi Wu participated in revision of the manuscript. Wenyi Wang analyzed data and wrote the manuscript. The manuscript was approved by all authors.

Conflicts of Interest: The authors declare that there is no conflict of interest. 


\section{References}

1. Holton, T.A.; Cornish, E.C. Genetics and biochemistry of anthocyanin biosynthesis. Plant Cell 1995, 7, 1071-1083. [CrossRef] [PubMed]

2. Grotewold, E. The genetics and biochemistry of floral pigments. Annu. Rev. Plant Biol. 2006, 57, 761-780. [CrossRef] [PubMed]

3. Yoshikazu, T.; Sasaki, N.; Ohmiya, A. Biosynthesis of plant pigments: Anthocyanins, betalains and carotenoids. Plant J. 2008, 54, 733-749.

4. Pourcel, L.; Routaboul, J.M.; Cheynier, V.; Lepiniec, L.; Debeaujon, I. Flavonoid oxidation in plants: From biochemical properties to physiological functions. Trends Plant Sci. 2007, 12, 29-36. [CrossRef] [PubMed]

5. Brenda, W.-S. Flavonoid biosynthesis. A colorful model for genetics, biochemistry, cell biology, and biotechnology. Plant Physiol. 2001, 126, 485-493.

6. Katsumoto, Y.; Fukuchi-Mizutani, M.; Fukui, Y.; Brugliera, F.; Holton, T.A.; Karan, M.; Nakamura, N.; Yonekura-Sakakibara, K.; Togami, J.; Pigeaire, A.; et al. Engineering of the rose flavonoid biosynthetic pathway successfully generated blue-hued flowers accumulating delphinidin. Plant Cell Physiol. 2007, 48, 1589-1600. [CrossRef] [PubMed]

7. Noda, Y.; Kneyuki, T.; Igarashi, K.; Mori, A.; Packer, L. Antioxidant activity of nasunin, an anthocyanin in eggplant peels. Toxicology 2000, 148, 119-123. [CrossRef]

8. Doganlar, S.; Frary, A.; Daunay, M.C.; Lester, R.N.; Tanksley, S.D. A comparative genetic linkage map of eggplant (Solanum melongena) and its implications for genome evolution in the Solanaceae. Genetics 2002, 161, 1697-1711. [PubMed]

9. Hirakawa, H.; Shirasawa, K.; Miyatake, K.; Nunome, T.; Negoro, S.; Ohyama, A.; Yamaguchi, H.; Sato, S.; Isobe, S.; Tabata, S.; et al. Draft genome sequence of eggplant (Solanum melongena L.): The representative solanum species indigenous to the old world. DNA Res. 2014, 21, 649-660. [CrossRef] [PubMed]

10. Joseph, M.; Grotewold, E.; Koes, R. How genes paint flowers and seeds. Trends Plant Sci. 1998, 3, $212-217$.

11. Francisco, D.; Jiménez, A.R.; Paredes-López, O. Natural pigments: Carotenoids, anthocyanins, and betalains-Characteristics, biosynthesis, processing, and stability. Crit. Rev. Food Sci. Nutr. 2000, 40, 173-289.

12. Adami, M.; De Franceschi, P.; Brandi, F.; Liverani, A.; Giovannini, D.; Rosati, C.; Tartarini, S. Identifying a carotenoid cleavage dioxygenase (CCD4) gene controlling yellow/white fruit flesh color of peach. Plant Mol. Boil. Rep. 2013, 31, 1166-1175. [CrossRef]

13. Liu, H.; Jiao, J.; Liang, X.; Liu, J.; Meng, H.; Chen, S.; Cheng, Z. Map-based cloning, identification and characterization of the $\mathrm{w}$ gene controlling white immature fruit color in cucumber (Cucumis sativus L.). Theor. Appl. Genet. 2016, 129, 1247-1256. [CrossRef] [PubMed]

14. Wei, Y.; Wan, H.; Wu, Z.; Wang, R.; Ruan, M.; Ye, Q.; Li, Z.; Zhou, G.; Yao, Z.; Yang, Y. A comprehensive analysis of carotenoid cleavage dioxygenases genes in Solanum lycopersicum. Plant Mol. Boil. Rep. 2016, 34, 512-523. [CrossRef]

15. Gert, F.; Martens, S. Metabolic engineering and applications of flavonoids. Curr. Opin. Biotechnol. 2001, 12, 155-160.

16. Springob, K.; Nakajima, J.; Yamazaki, M.; Saito, K. Recent advances in the biosynthesis and accumulation of anthocyanins. Nat. Prod. Rep. 2003, 20, 288-303. [CrossRef] [PubMed]

17. Tai, D.; Tian, J.; Zhang, J.; Song, T.; Yao, Y. A Malus crabapple chalcone synthase gene, McCHS, regulates red petal color and flavonoid biosynthesis. PLoS ONE 2014, 9, e110570. [CrossRef] [PubMed]

18. Yoshikazu, T.; Tsuda, S.; Kusumi, T. Metabolic engineering to modify flower color. Plant Cell Physiol. 1998, 39, 1119-1126.

19. Brenda, W.-S. Evidence for enzyme complexes in the phenylpropanoid and flavonoid pathways. Physiol. Plant. 1999, 107, 142-149.

20. Ahmadiani, N.; Robbins, R.J.; Collins, T.M.; Giusti, M.M. Anthocyanins contents, profiles, and color characteristics of red cabbage extracts from different cultivars and maturity stages. J. Agric. Food Chem. 2014, 62, 7524-7531. [CrossRef] [PubMed]

21. Yan, M.L.; Liu, X.J.; Guan, C.Y.; Chen, X.B.; Liu, Z.S. Cloning and expression analysis of an anthocyanidin synthase gene homolog from Brassica juncea. Mol. Breed. 2011, 28, 313-322. [CrossRef] 
22. Heppel, S.C.; Jaffé, F.W.; Takos, A.M.; Schellmann, S.; Rausch, T.; Walker, A.R.; Bogs, J. Identification of key amino acids for the evolution of promoter target specificity of anthocyanin and proanthocyanidin regulating MYB factors. Plant Mol. Biol. 2013, 82, 457-471. [CrossRef] [PubMed]

23. Zhao, D.; Jun, T. Recent advances on the development and regulation of flower color in ornamental plants. Front. Plant Sci. 2015, 6, 261. [CrossRef] [PubMed]

24. Xu, W.; Dubos, C.; Lepiniec, L. Transcriptional control of flavonoid biosynthesis by MYB-bHLH-WDR complexes. Trends Plant Sci. 2015, 20, 176-185. [CrossRef] [PubMed]

25. Ramachandra, R.S.; Ravishankar, G.A. Plant cell cultures: Chemical factories of secondary metabolites. Biotechnol. Adv. 2002, 20, 101-153. [CrossRef]

26. Prinsi, B.; Negri, A.S.; Quattrocchio, F.M.; Koes, R.E.; Espen, L. Proteomics of red and white corolla limbs in petunia reveals a novel function of the anthocyanin regulator ANTHOCYANIN1 in determining flower longevity. J. Proteom. 2016, 131, 38-47. [CrossRef] [PubMed]

27. Butelli, E.; Titta, L.; Giorgio, M.; Mock, H.P.; Matros, A.; Peterek, S.; Schijlen, E.G.; Hall, R.D.; Bovy, A.G.; Luo, J.; et al. Enrichment of tomato fruit with health-promoting anthocyanins by expression of select transcription factors. Nat. Biotechnol. 2008, 26, 1301-1308. [CrossRef] [PubMed]

28. Allan, A.C.; Hellens, R.P.; Laing, W.A. MYB transcription factors that colour our fruit. Trends Plant Sci. 2008, 13, 99-102. [CrossRef] [PubMed]

29. Feng, S.; Wang, Y.; Yang, S.; Xu, Y.; Chen, X. Anthocyanin biosynthesis in pears is regulated by a R2R3-MYB transcription factor PyMYB10. Planta 2010, 232, 245-255. [CrossRef] [PubMed]

30. Pérez-Díaz, J.R.; Pérez-Díaz, J.; Madrid-Espinoza, J.; González-Villanueva, E.; Moreno, Y.; Ruiz-Lara, S. New member of the R2R3-MYB transcription factors family in grapevine suppresses the anthocyanin accumulation in the flowers of transgenic tobacco. Plant Mol. Biol. 2016, 90, 63-76. [CrossRef] [PubMed]

31. Elomaa, P.; Uimari, A.; Mehto, M.; Albert, V.A.; Laitinen, R.A.; Teeri, T.H. Activation of anthocyanin biosynthesis in Gerbera hybrida (Asteraceae) suggests conserved protein-protein and protein-promoter interactions between the anciently diverged monocots and eudicots. Plant Physiol. 2003, 133, 1831-1842. [CrossRef] [PubMed]

32. Zhou, H.; Peng, Q.; Zhao, J.; Owiti, A.; Ren, F.; Liao, L.; Wang, L.; Deng, X.; Jiang, Q.; Han, Y. Multiple R2R3-MYB transcription factors involved in the regulation of anthocyanin accumulation in peach flower. Front. Plant Sci. 2016, 7, 1557. [CrossRef] [PubMed]

33. Barchi, L.; Lanteri, S.; Portis, E.; Valè, G.; Volante, A.; Pulcini, L.; Ciriaci, T.; Acciarri, N.; Barbierato, V.; Toppino, L.; et al. A RAD tag derived marker based eggplant linkage map and the location of QTLs determining anthocyanin pigmentation. PLoS ONE 2012, 7, e43740. [CrossRef] [PubMed]

34. Cericola, F.; Portis, E.; Lanteri, S.; Toppino, L.; Barchi, L.; Acciarri, N.; Pulcini, L.; Sala, T.; Rotino, G.L. Linkage disequilibrium and genome-wide association analysis for anthocyanin pigmentation and fruit color in eggplant. BMC Genom. 2014, 15, 896. [CrossRef] [PubMed]

35. Jaakola, L.; Määttä, K.; Pirttilä, A.M.; Törrönen, R.; Kärenlampi, S.; Hohtola, A. Expression of genes involved in anthocyanin biosynthesis in relation to anthocyanin, proanthocyanidin, and flavonol levels during bilberry fruit development. Plant Physiol. 2002, 130, 729-739. [CrossRef] [PubMed]

36. Dooner, H.K.; Robbins, T.P.; Jorgensen, R.A. Genetic and developmental control of anthocyanin biosynthesis. Annu. Rev. Genet. 1991, 25, 173-199. [CrossRef] [PubMed]

(C) 2018 by the authors. Licensee MDPI, Basel, Switzerland. This article is an open access article distributed under the terms and conditions of the Creative Commons Attribution (CC BY) license (http://creativecommons.org/licenses/by/4.0/). 